\title{
RENDIMENTO EM MADEIRA SERRADA E QUANTIFICAÇÃO DE RESÍDUOS PARA TRÊS ESPÉCIES TROPICAIS
}

\author{
Cândido Pietro Biasi*, Márcio Pereira da Rocha** \\ *Eng. Florestal, M.Sc., INFLOR - Consultoria Florestal - pbiasi@terra.com.br \\ **Eng. Florestal, Dr., Depto. Engenharia e Tecnologia Florestal, UFPR - mprocha@ufpr.br \\ Recebido para publicação: 26/04/2006 - Aceito para publicação: 06/11/2006
}

\begin{abstract}
Resumo
Este trabalho teve o objetivo de avaliar o rendimento em madeira serrada e geração de resíduos no desdobro das espécies cedrinho (Erisma uncinatum), cambará (Qualea albiflora) e itaúba (Mezilaurus $i t a u b a$ ). Foram desdobradas toras das três espécies em quatro classes diamétricas, variando de 31 a 70 $\mathrm{cm}$ de diâmetro, seguindo uma mesma metodologia de desdobro. Foram determinados o rendimento em madeira serrada e o volume de resíduos. O rendimento em madeira serrada não apresentou diferenças estatísticas entre classes diamétricas para as três espécies estudadas. As espécies cedrinho e itaúba apresentaram o maior rendimento na classe diamétrica de 51 a $60 \mathrm{~cm}$. Já a itaúba apresentou a tendência de aumentar o rendimento em madeira serrada com o aumento do diâmetro das toras. A espécie cambará, mesmo não apresentando diferença estatística, foi a que apresentou o melhor rendimento em madeira serrada. A espécie itaúba apresentou menor rendimento e, conseqüentemente, maior geração de resíduos. Toras de maiores diâmetros de cedrinho e itaúba apresentaram defeitos que provocaram a redução no rendimento. Em termos de geração de resíduos, somente a itaúba foi estatisticamente diferente das demais.
\end{abstract}

Palavras-chave: Madeira serrada; rendimento; cedrinho; cambará; itaúba.

\begin{abstract}
Yield in sawnwood and quantification of residues for three tropical species. The purpose of this work was to evaluate the yield in sawnwood and the generation of residues from sawing of the following species: cedrinho (Erisma uncinatum), cambará (Qualea albiflora) and itaúba (Mezilaurus itauba). Logs of three species were sawed in four diametric classes, ranging from 31 to $70 \mathrm{~cm}$, using the same sawing methods. The yield in sawnwood as well as the volume of residues were determined. yield in sawnwood didn't show statistic differences between diametrical classes for the three studied species. The cedrinho and itaúba species showed a higher yield in the diametric classes from 51 to $60 \mathrm{~cm}$. On the other hand, itaúba species showed the tendency to increase the yield in sawnwood with the increasing of logs' diameter. Although presenting no statistic differences, the species that showed the better yield in sawnwood was the cambará. The itaúba species presented lesser yield, and so, high generation of residues. The logs of larger diameter of cedrinho and itaúba presented defects that resulted in yield reduction. In terms of the residues' generation, only the itaúba was statistically different from the others species.

Keywords: Sawnwood; yield; residues; tree species.
\end{abstract}

\section{INTRODUÇÃO}

A madeira é um material que vem sendo largamente utilizado pela humanidade ao longo da história. No Brasil, que é um país rico em florestas nativas, convive-se com a exploração desses recursos, às vezes de maneira não-racional.

Além de grande produtor, o Brasil é também um grande consumidor de madeiras tropicais. A Amazônia brasileira representa uma área de aproximadamente 3,6 milhões de $\mathrm{km}^{2}$, o que equivale a $42 \%$ da área total do Brasil, onde se estima que existam cerca de 6.000 espécies arbóreas, cuja utilização comercial é limitada em aproximadamente 100, enquanto que o número de madeiras exportadas para os mercados mundiais é inferior a 13 (PECK, 1983). Esse grande potencial madeireiro da região pode gerar muitos benefícios socioeconômicos através de estudos de caracterização tecnológica, visando difundir o 
maior número possível de espécies potenciais, com finalidades diversas e específicas, para uso nos mercados interno e externo.

No Brasil, sob a denominação de Amazônia Legal, está compreendida uma região que inclui os estados do Amazonas, Pará, Rondônia, Acre, Roraima, Amapá e parte dos estados do Maranhão, Mato Grosso e Tocantins.

A região amazônica é considerada uma das maiores reservas de madeiras tropicais do mundo. Essa região desempenha um papel de elevada importância como fornecedora de madeiras duras para os mercados internacional e nacional, sendo neste último caso principalmente para as regiões Sudeste e Sul do país. A utilização desse potencial madeireiro sempre foi conduzida no sentido de se explorar aquelas espécies de emprego já consagrado nos referidos mercados.

Ao lado dessas madeiras tradicionais, toda a região amazônica apresenta ainda um grande potencial de madeiras que terão, certamente, uma ampla aceitação no comércio se forem mais bem estudadas sob os pontos de vista anatômico e tecnológico. Neste sentido, muitos estudos já têm sido desenvolvidos para um melhor conhecimento das madeiras amazônicas.

A melhoria do nível tecnológico industrial é condição essencial para o aproveitamento máximo da matéria-prima e está diretamente relacionado com a conservação dos recursos florestais. Falta ao Brasil apoio tecnológico para que a atividade madeireira obtenha melhor aproveitamento da matériaprima, especialmente no sistema avançado de utilização da madeira. Assim, a eficiência técnica e econômica dos processos de transformação do recurso florestal em produtos pela indústria madeireira é fator básico para sua sobrevivência. A indústria de transformação da madeira que não estiver preocupada em melhorar seus rendimentos e, conseqüentemente, viabilizar seus custos de produção, dando uma utilização total aos resíduos gerados no processo, assume um sério risco de perder em competitividade e paralisar as suas atividades.

De acordo com Barbosa et al. (2001), o setor produtivo de madeira e derivados na Amazônia enfrenta enormes dificuldades para tornar seus produtos competitivos no mercado, que está cada vez mais globalizado. Problemas como parque tecnológico defasado, seletividade de espécies florestais, mão-deobra desqualificada e empresas descapitalizadas são recorrentes, e novos desafios são gerados à medida que o setor produtivo é mais exigido pelo mercado.

De acordo com ABIMCI (2003), o segmento de mais alta participação brasileira é o de madeira serrada, com a quarta posição no ranking mundial. Em madeira na forma de tora, o Brasil não aparece como importador, uma vez que a cadeia está bem abastecida de todas as quantidades e qualidades desse tipo de insumo. Também não ocupa posição de destaque em exportações, o que é um bom sinal: a madeira fica no país para ser beneficiada e, posteriormente, exportada com maior agregação de valor.

As espécies florestais na região amazônica são numerosas, talvez mais de 1.000, mas algumas dessas espécies não são utilizadas devido à presença de características indesejáveis, tais como grande peso e dureza, sílica, óleos, resinas, falta de resistência e durabilidade. Muitas outras espécies não são utilizadas simplesmente porque suas características físicas e mecânicas ainda não são conhecidas (REIS, 1989).

Estima-se que cerca de 250 espécies têm sido utilizadas pelas serrarias. A maioria dessas espécies possui mercado local muito limitado, e cerca de 80 espécies são vendidas no mercado brasileiro. As espécies utilizadas para fins de exportação pelas serrarias, indústrias de compensados e laminados são cerca de 50 . Destas, mogno, virola, sucupira, cedro, ipê, cerejeira, andiroba, louro, angelim e muiracatiara contribuem com 75\% do total de madeira serrada exportada (REIS, 1989). Segundo o mesmo autor, os principais produtos da indústria de madeira dura do Brasil são madeiras serradas, incluindo madeira para construção, madeira classificada, assoalhos, painéis e madeira não-classificada, laminados, compensados e móveis.

No mercado interno, destacam-se também o cedrinho, o cambará e a itaúba, que vem se tornando uma das espécies mais caras para madeira de construção.

Em função da deficiência tecnológica e do pouco conhecimento das espécies, talvez o maior problema enfrentado pela indústria de madeira serrada seja o baixo aproveitamento da matéria-prima, o que acarreta em aumento do custo do produto final e uma grande geração de resíduos.

O rendimento do desdobro de toras em produtos acabados sofre variações com o tipo e tamanho da indústria madeireira, com as espécies utilizadas e com as características dos produtos beneficiados (IBDF, 1998; PEIXOTO; IWAKIRI, 1984; OLIVEIRA et al., 2003).

De acordo com Vale et al. (1994) citado por Oliveira et al. (2003), 80\% do volume de madeira produzido na Amazônia provêm de pequenas empresas com baixo padrão tecnológico, levando a um desperdício acima dos níveis aceitáveis. Além disso, a madeira é processada basicamente em nível 
primário, o que resulta em um produto de baixo valor agregado, reduzindo as possibilidades de maiores receitas.

Por vários anos, a indústria madeireira tem considerado os resíduos como subprodutos problemáticos do processamento de madeira e procurado desfazer-se deles, utilizando-os para aterro (entulho, lixo) ou os incinerando em queimadores, apenas com a finalidade de desocupar os pátios sem realizar aproveitamento energético. Entretanto, essas soluções têm se convertido recentemente em sérios problemas ambientais. Além disso, a questão dos crescentes aumentos nos custos dos insumos energéticos tem levado as indústrias a pensarem nas vantagens do aproveitamento dos resíduos como fonte alternativa de combustível ou de utilizá-los como matéria-prima para outros produtos, quais sejam a produção de celulose ou de chapas de composição (FONTES, 1994).

Fontes (1989), citado por Fontes (1994), demonstra que o índice de aproveitamento das toras de madeiras no processamento industrial sofre variações em função do tipo e tamanho da indústria, equipamentos e espécies utilizadas, indicando que as principais perdas são as costaneiras e o pó-de-serra (serragem). Esse índice pode variar de 25 a $70 \%$ do volume da tora. Nas serrarias, além da serragem e costaneiras, as peças são aparadas para padronizar a largura, o comprimento e a espessura, produzindo aparas, cavacos e/ou maravalhas. Nas laminadoras, o maior resíduo é formado pelas lâminas iniciais com tamanhos irregulares e defeitos decorrentes do formato das toras.

A quantidade real de resíduos obtida com a fabricação de produtos de madeira é distinta de uma instalação industrial para outra e depende de vários fatores, começando pelas propriedades da madeira, passando pelo tipo e sistema de produção adotado pela indústria, até o produto final acabado (FONTES, 1994). Segundo o mesmo autor, considerando-se que 50 a $70 \%$ do volume de madeira em tora que entra em uma serraria para ser convertido em madeira serrada resultem na forma de casca, costaneiras, refilos, aparas e serragem, seria irracional não promover o aproveitamento máximo desses subprodutos. Estes, num primeiro momento, podem ser tidos apenas como rejeitos do processo, mas seguramente podem sair da serraria como matéria-prima para a produção de pastas e celulose, de chapas e de compostos orgânicos, bem como promover a auto-suficiência energética da própria indústria.

Em projetos de serrarias, a otimização no uso de toras tem se baseado em vários elementos, os quais requerem um conhecimento detalhado da matéria-prima (toras) e de definições a serem tomadas a partir de simulações utilizando modelos de corte. A simulação utilizando modelos de corte permite obter informações sobre rendimento, tipo de produto, qualidade e valores. Essas informações formam uma base importante para as análises, principalmente econômico-financeiras, e finalmente para as definições de engenharia e de investimentos, determinantes à competitividade e ao sucesso do negócio (WIPIESKI et al., 2002).

Nas serrarias baseadas em projetos convencionais, a escolha da maneira pela qual as toras serão processadas depende de experiência dos operadores. Na prática, e na grande maioria dos casos, a decisão é aleatória. O posicionamento das toras, o número de cortes, o dimensionamento dos blocos e pranchas visando a obtenção de produtos mais adequados e a eliminação dos defeitos das toras, são alguns dos fatores que afetam diretamente o rendimento do processo de corte, os produtos obtidos e, conseqüentemente, os custos de produção e receitas geradas. Na realidade, é um conjunto de fatores que dificilmente pode ser otimizado sem a existência de ferramentas adequadas (WIPIESKI et al., 2002). Segundo os autores, atualmente encontram-se disponíveis no mercado sistemas capazes de reconhecer e interpretar automaticamente as diferenças existentes entre as toras a serem processadas, assegurando maior racionalidade no posicionamento e nos diferentes cortes a serem efetuados. Trata-se de sistemas de alta tecnologia, os quais possibilitam a maximização no aproveitamento da matéria-prima. Embora disponíveis, esses sistemas em geral são dispendiosos, e em serrarias de pequeno e médio porte dificilmente podem ser justificados em uma análise econômica.

Dentro desse contexto, este trabalho procurou levantar dados e informações técnicas referentes ao rendimento em madeira serrada e geração de resíduos, comparando-se três espécies tropicais em quatro classes diamétricas.

\section{MATERIAL E MÉTODOS}

\section{Espécies estudadas}

Para este estudo, foram selecionadas três espécies de importância econômica na Região Amazônica, sendo elas: cedrinho (Erisma uncinatum), cambará (Qualea albiflora) e itaúba (Mezilaurus itauba). O cedrinho, com densidade aparente a $15 \%$ de $0,59 \mathrm{~g} / \mathrm{cm}^{3}$, é utilizado em construção civil e 
naval, móveis, molduras, carpintaria comum, fabricação de compensados, miolo de portas, molduras, rodapés, embalagens, ripas, sarrafos, fôrma para concreto, cabos de vassoura, chapas, caixas, engradados e outros (LORENZI, 1998). O cambará, com densidade média aparente a $12 \%$ de $0,68 \mathrm{~g} / \mathrm{cm}^{3}$, é indicado para uso interno em construção civil, como caibros, vigas, esteios, ripas etc, para confecção de móveis, brinquedos, cabos de ferramentas e instrumentos agrícolas (LORENZI, 1998). A itaúba, com densidade aparente a $15 \%$ de $0,96 \mathrm{~g} / \mathrm{cm}^{3}$, é indicada para uso em construções externas, tais como estruturas de pontes, postes, moirões, dormentes, cruzetas, defensas, estacas; partes internas em construção civil, como vigas, caibros, ripas, marcos ou batentes de portas e janelas, esquadrias, caixilhos, tacos e tábuas de assoalho; mobiliário comum, construção naval, barcos, carrocerias, tanoaria, peças torneadas, cabos de ferramentas e implementos agrícolas etc (LORENZI, 1998).

\section{Local do estudo}

Este estudo foi realizado em uma serraria localizada no município de Sinop, no estado do Mato Grosso. Nessa serraria, após o desdobro das toras, as peças brutas são processadas em madeiras aplainadas como forros, divisórias, assoalho, batentes e vistas, entre outras destinações. As informações necessárias para a realização deste trabalho foram coletadas diretamente na serraria, durante o $2^{\circ}$ semestre do ano de 2004 e o $1^{\circ}$ semestre de 2005.

A serraria constitui-se de uma serra-fita com diâmetro de volantes de $1,10 \mathrm{~m}$ e potência do motor de $40 \mathrm{HP}$, com a qual foi realizado o desdobro principal das toras. A canteagem ou refilo foi realizada numa serra circular com disco de $30 \mathrm{~cm}$ de diâmetro e potência do motor de 15 HP. Para o destopo foi utilizada uma destopadeira com disco de $25 \mathrm{~cm}$ de diâmetro e potência do motor de $35 \mathrm{HP}$. Além desses equipamentos de desdobro, a serraria possui um exaustor com potência do motor de $15 \mathrm{HP}$, para a retirada da serragem proveniente da serra-fita e da serra circular. Basicamente a empresa trabalha com várias espécies, sendo o cedrinho, cambará e itaúba as mais utilizadas.

\section{Obtenção e seleção das toras}

As toras foram adquiridas por intermédio de extratores de toras, ou seja, empreiteiros que terceirizam a exploração florestal e vendem para as madeireiras conforme as espécies utilizadas pelas mesmas, oriundas de exploração de Plano de Manejo Florestal Sustentado ou desmate devidamente legalizado.

Foram selecionadas 60 toras em 4 classes diamétricas, sendo 20 toras para cada espécie estudada, dividindo-se em 5 toras para cada classe de diâmetro, conforme tabela 1 . As toras de cada classe diamétrica foram separadas por lote e espécies, recebendo pinturas de diferentes cores em seus respectivos topos (Figura 1). Antes do desdobro, todas as toras tiveram suas circunferências medidas na ponta fina e ponta grossa para obtenção do diâmetro médio, bem como para posterior classificação segundo a sua classe diamétrica por espécie e para o cálculo do seu volume. Todas as toras das três espécies apresentaram comprimento de $2,75 \mathrm{~m}$.

Tabela 1. Número de toras, separadas por classe diamétrica, para as espécies cedrinho, itaúba e cambará. Table 1. Amount of logs per diametric classes for the species cedrinho, itauba and cambara.

\begin{tabular}{lcccc}
\hline Classe & Espécies & Número de toras & Diâmetro (cm) & Comprimento (m) \\
\hline 1 & Cedrinho & 5 & $31,0-40,0$ & 2,75 \\
2 & & 5 & $41,0-50,0$ & 2,75 \\
3 & 5 & $51,0-60,0$ & 2,75 \\
4 & 5 & $61,0-70,0$ & 2,75 \\
\hline 1 & & 5 & $31,0-40,0$ & 2,75 \\
2 & 5 & $41,0-50,0$ & 2,75 \\
3 & Cambará & 5 & $51,0-60,0$ & 2,75 \\
4 & & 5 & $61,0-70,0$ & 2,75 \\
\hline 1 & & 5 & $31,0-40,0$ & 2,75 \\
2 & 5 & $41,0-50,0$ & 2,75 \\
3 & Itaúba & $51,0-60,0$ & 2,75 \\
4 & & $61,0-70,0$ & 2,75 \\
\hline Total & 5 & & \\
\hline
\end{tabular}



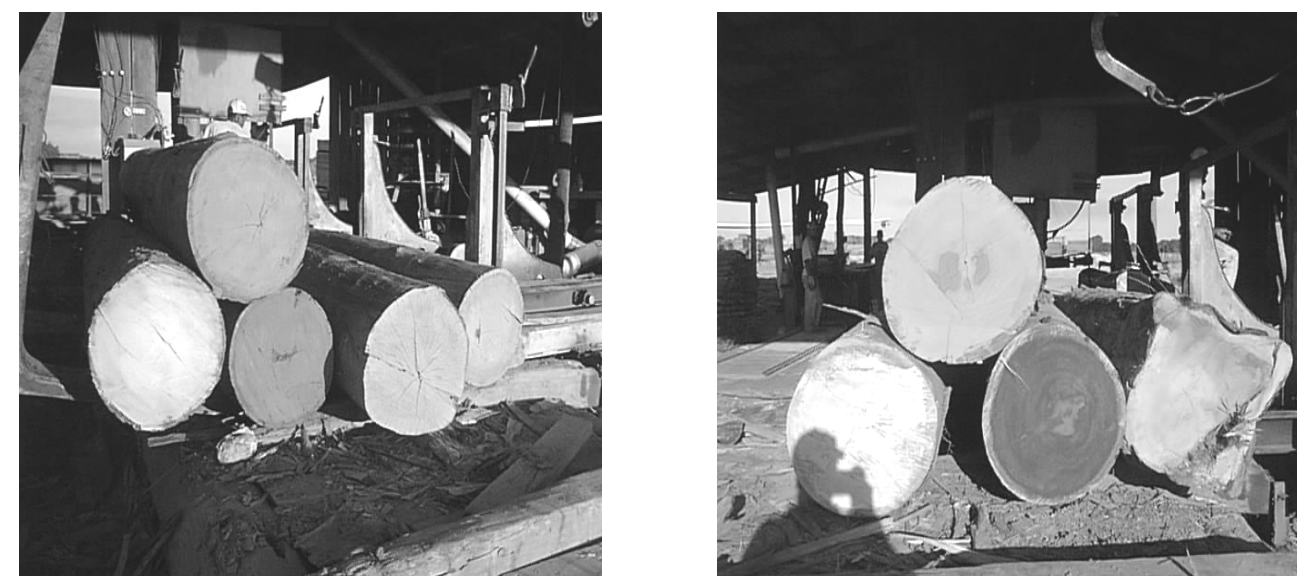

Figura 1. Lotes de toras por diferentes classes de diâmetros e espécies.

Figure 1. Portion of logs per different diametric classes and species.

\section{Desdobro das toras}

As toras foram admitidas no processo de desdobro passando pela serra-fita, onde foram realizados os cortes, retirando-se as costaneiras e a primeira tábua, formando-se um semibloco. Posteriormente, o semibloco foi desdobrado em cortes sucessivos originando tábuas. As tábuas obtidas seguiram para a serra circular de mesa, onde foram refiladas em tábuas com larguras de 10,5 cm. A operação de destopo das tábuas só foi realizada nas peças que apresentaram defeitos como rachaduras, apodrecimentos e outros. Depois de alinhadas e bitoladas, as tábuas foram enviadas ao processo de secagem. Na figura 2, é apresentada a seqüência das operações de desdobro.
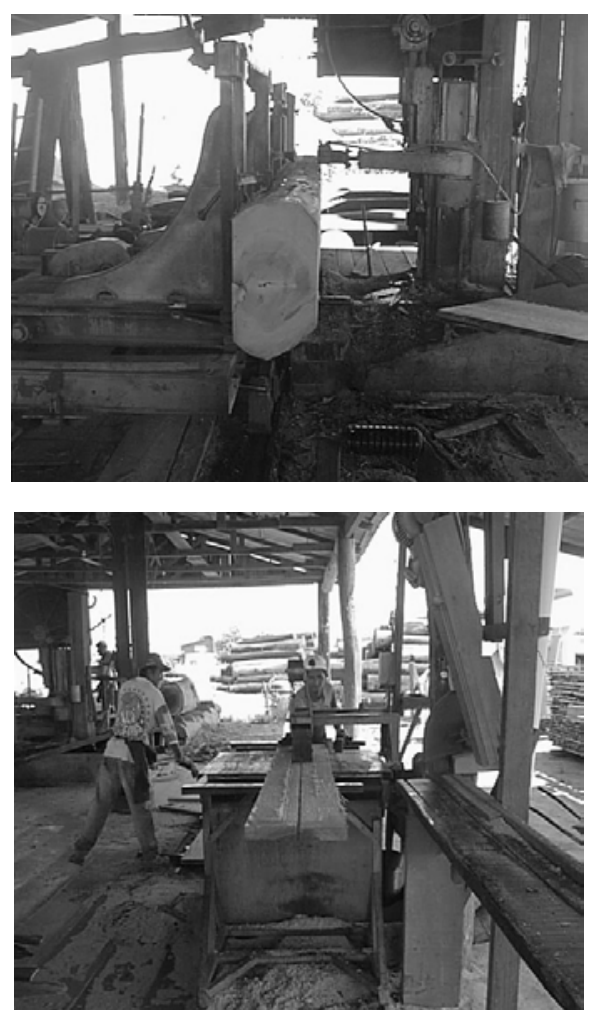

Figura 2. Seqüência de operações de desdobro das toras Figure 2. Sequence of logs sawing.
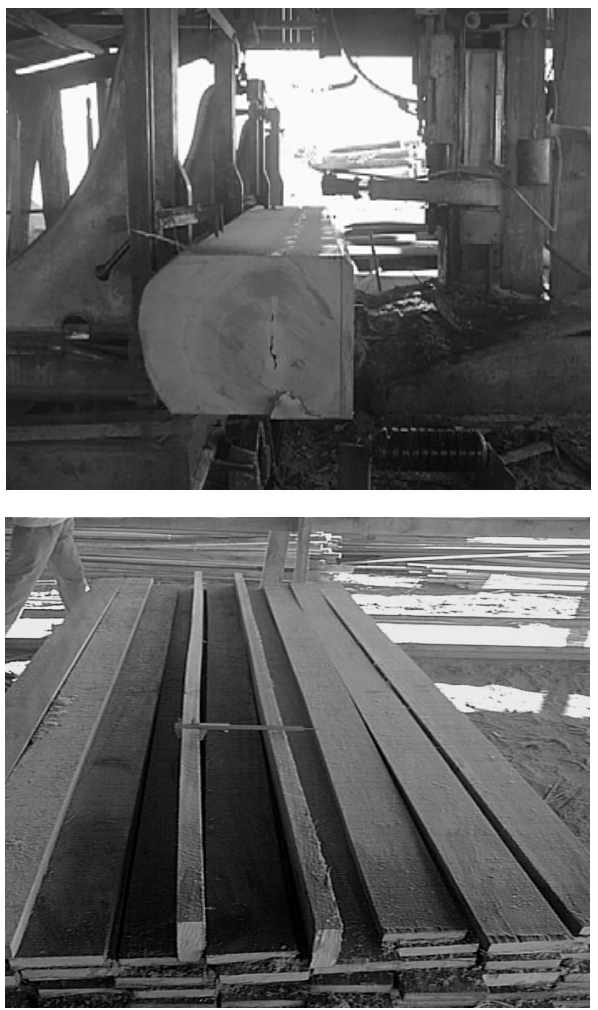


\section{Rendimento volumétrico da madeira serrada}

Após o desdobro, todas as tábuas obtidas de cada tora foram agrupadas separadamente. Como todas as tábuas foram desdobradas nas dimensões de $10,5 \mathrm{~cm}$ de largura, $2,6 \mathrm{~cm}$ de espessura e $275 \mathrm{~cm}$ de comprimento e são usinadas considerando-se estas medidas nominais, o volume serrado de cada tora foi obtido através da contagem das tábuas, cujo resultado foi multiplicado pelo volume nominal das mesmas. Somente foram medidos os comprimentos das tábuas que, por algum tipo de defeito, foram destopadas em comprimentos menores.

\section{Obtenção do volume de resíduos}

Para a obtenção do volume de resíduos produzido, sejam costaneiras, refilos, destopos ou serragem, foram calculados a largura e o comprimento de cada peça que passava na serra-fita, multiplicando-se os valores obtidos pela espessura de corte do fio da serra, chegando-se ao volume total de serragem no fim de cada tora que era desdobrada na serra-fita. $\mathrm{O}$ mesmo procedimento foi realizado para as peças que passavam na serra circular, para obter-se o volume de serragem nas operações de refilo. O volume de costaneiras e refilos foi obtido através do volume bruto de cada tora, subtraindo-se o volume de madeira serrada e o volume de serragem calculado.

\section{Análise estatística}

Foi conduzida uma análise estatística simples, com teste de comparação de médias baseado na análise de variância. O teste de comparação de médias foi baseado no método de Tukey a 5\% de probabilidade. Os principais tratamentos foram o efeito da espécie de madeira e a classe diamétrica das toras. As variáveis analisadas foram rendimento e geração de resíduos.

\section{RESULTADOS E DISCUSSÃO}

\section{Rendimento em madeira serrada} estudadas.

$\mathrm{Na}$ tabela 2, são apresentados os resultados da análise de variância entre as três espécies

Tabela 2. Análise de variância para o rendimento em madeira serrada, soma de quadrados tipo III, entre as espécies cedrinho (E. uncinatum), cambará (Q. albiflora) e itaúba (M. itauba).

Table 2. Analysis of variance for yield in sawnwood, sum of square type III, between species cedrinho (E. uncinatum), cambará (Q. albiflora) and itaúba (M. itauba).

\begin{tabular}{lcccc}
\hline \multirow{2}{*}{ Fonte } & GL & \multicolumn{3}{c}{ Quadrado médio/f } \\
\cline { 3 - 5 } & & Cedrinho & Cambará & Itaúba \\
\hline Classe diamétrica & 3 & $23,3413 / 0,68$ & $32,6085 / 1,54$ & $64,1803 / 1,69$ \\
Resíduo & 16 & 34,4940 & 21,1298 & 38,0308 \\
\hline Total & 19 & & & \\
\hline
\end{tabular}

Cedrinho (E. uncinatum)

Na tabela 3, é apresentada a análise de variância do rendimento em madeira serrada para a espécie cedrinho, onde se pode observar que não houve diferença estatística entre os rendimentos das quatro classes diamétricas estudadas, para um nível de probabilidade de $5 \%$.

Tabela 3. Análise de variância para o rendimento em madeira serrada entre classes diamétricas, soma de quadrados tipo III, para a espécie cedrinho (Erisma uncinatum).

Table 3. Analysis of variance for yield in sawnwood between diametric classes, sum of square type III, for the cedrinho species (Erisma uncinatum).

\begin{tabular}{lccccc}
\hline Fonte & Soma dos quadrados & GL & Quadrado médio & Valor-F & Valor-P \\
\hline Efeito principal: & & & & & \\
Classe diamétrica & 70,0239 & 3 & 23,3413 & 0,68 & 0,5789 \\
Residual & 551,903 & 16 & 34,494 & & \\
\hline Total (corrigido) & 621,927 & 19 & & & \\
\hline
\end{tabular}


$\mathrm{Na}$ tabela 4, são apresentados os resultados para as 4 classes diamétricas da espécie cedrinho $(E$. uncinatum), com seus respectivos rendimentos. Observa-se nessa tabela que, para o cedrinho, a média de rendimento entre as 4 classes diamétricas aproximou-se de $60 \%$. Apesar da não-existência de diferença estatística entre as classes diamétricas, a classe 3 apresentou maior rendimento e, assim, considerando uma situação de grande produção, pode gerar grandes diferenças (Tabela 3).

Tabela 4. Volume bruto das toras $\left(\mathrm{m}^{3}\right)$, volume serrado $\left(\mathrm{m}^{3}\right)$ e rendimento médio em madeira serrada $(\%)$ para 4 classes da espécie cedrinho (E. uncinatum).

Table 4. Gross volume of logs $\left(\mathrm{m}^{3}\right)$, sawnwood volume $\left(\mathrm{m}^{3}\right)$ and average yield in sawnwood $(\%)$ for 4 classes of cedrinho species (E. uncinatum).

\begin{tabular}{lccc}
\hline Classe & Volume bruto $\left(\mathbf{m}^{\mathbf{3}}\right)$ & Volume serrado $\left(\mathbf{m}^{\mathbf{3}}\right)$ & Rendimento médio (\%) \\
\hline 1 & 1,4725 & 0,8410 & $57,30 \mathrm{a}$ \\
2 & 2,2694 & 1,3814 & $60,52 \mathrm{a}$ \\
3 & 3,5310 & 2,1991 & $62,40 \mathrm{a}$ \\
4 & 4,5605 & 2,7102 & $59,12 \mathrm{a}$ \\
\hline \multicolumn{4}{l}{ Média geral } \\
\multicolumn{4}{l}{} \\
\hline
\end{tabular}

No rendimento das classes 1, 2 e 3 ocorreu um aumento gradativo de acordo com o aumento do volume das toras. $\mathrm{O}$ menor valor médio na classe 1 deu-se em função das toras serem de diâmetro menor, ocorrendo muita perda em forma de refilo e costaneiras. Na classe 4, o volume médio das toras foi maior que o das demais classes $\left(4,5605 \mathrm{~m}^{3}\right)$, mas o rendimento foi menor $(59,12 \%)$ que o das classes 2 e 3 , ficando este entre as classes 1 e 2 . Esse valor menor no rendimento ocorreu em função das toras mais grossas apresentarem falhas internas, como rachaduras, ataques por insetos, podridão etc (Figura 3). Essas falhas conseqüentemente provocaram uma redução no rendimento em madeira serrada.
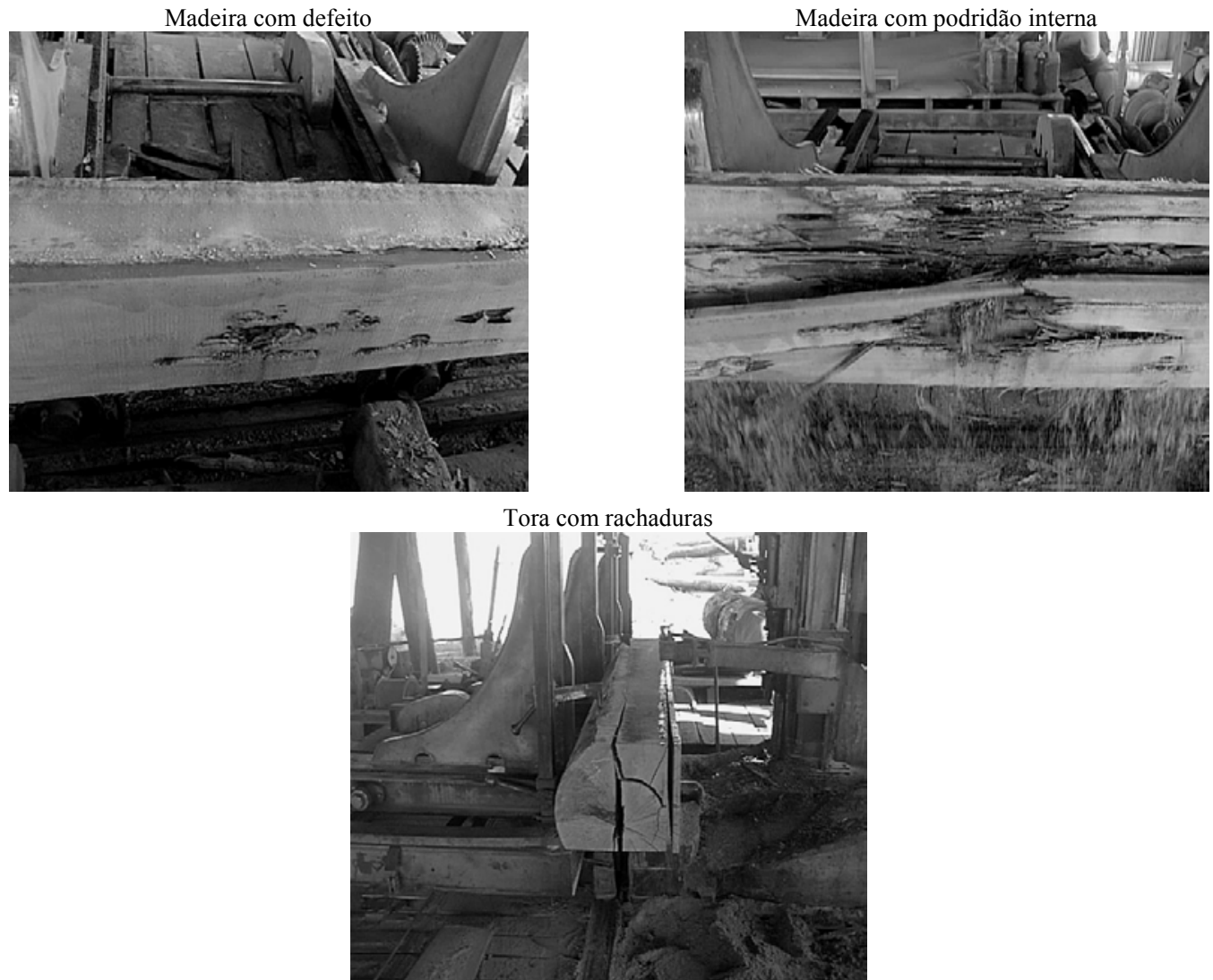

Figura 3. Falhas internas em toras de classe 4 observadas após desdobro na serra-fita.

Figure 3. Internal failures for class $4 \operatorname{logs}$ after sawing in the band saw. 
Segundo Rocha (2000), é normal em serrarias, as toras de menores diâmetros apresentarem menores rendimentos. Porém, ao trabalhar com madeira reflorestada (Eucalyptus grandis) com duas classes diamétricas ( 19 a $25 \mathrm{~cm}$ e 25 a $30 \mathrm{~cm}$ ), o autor obteve um rendimento médio superior para a classe de menores diâmetros. O mesmo foi observado neste estudo, onde o rendimento elevou-se da classe 1 para a 2 e da classe 2 para a 3, porém decrescendo da classe 3 para a 4 . Outro fator que deve ser levado em consideração é a pequena variedade de produtos obtidos das toras, o que pode fazer com que algumas classes diamétricas não sejam adequadas para as tábuas que se deseja obter das mesmas (MURARA JÚNIOR, 2005).

Porém, observa-se na figura 3 que, nesse caso, o fator determinante para a queda no rendimento foram defeitos provocados por agentes xilófagos nas toras de maior diâmetro dessa espécie. Muitas vezes, a aparência das toras pode não demonstrar um defeito interno na mesma, o qual só será evidenciado no momento do desdobro, conseqüentemente reduzindo o rendimento em madeira serrada.

\section{Cambará (Q. albiflora)}

$\mathrm{Na}$ tabela 5, é apresentada a análise de variância do rendimento em madeira serrada para a espécie cambará, onde se pode observar que, como o cedrinho, não houve diferença estatística entre os rendimentos das quatro classes diamétricas estudadas, para um nível de probabilidade de $5 \%$.

Tabela 5. Análise de variância para o rendimento em madeira serrada entre classes diamétricas, soma de quadrados tipo III, para a espécie cambará (Q. albiflora).

Table 5. Analysis of variance for the yield in sawnwood between diametric classes, sum of square type III for cambará species (Q. albiflora).

\begin{tabular}{lccccc}
\hline Fonte & Soma dos quadrados & GL & Quadrado médio & Valor-F & Valor-P \\
\hline Efeito principal: & & & & & \\
Classe diamétrica & 97,8254 & 3 & 32,6085 & 1,54 & 0,2419 \\
Residual & 338,076 & 16 & 21,1298 & & \\
\hline Total (corrigido) & 435,902 & 19 & & & \\
\hline
\end{tabular}

Na tabela 6, são apresentadas as 4 classes diamétricas de toras da espécie cambará (Q. albiflora), com 5 toras em cada classe, com seus respectivos rendimentos.

Tabela 6. Volume bruto das toras $\left(\mathrm{m}^{3}\right)$, volume serrado $\left(\mathrm{m}^{3}\right)$ e rendimento médio em madeira serrada $(\%)$ para 4 classes da espécie cambará (Q. albiflora).

Table 6. Gross volume of logs $\left(\mathrm{m}^{3}\right)$, sawnwood volume $\left(\mathrm{m}^{3}\right)$ and average yield in sawnwood $(\%)$ for 4 classes of cambará species (Q. albiflora).

\begin{tabular}{lccc}
\hline Classe & Volume bruto $\left(\mathbf{m}^{3}\right)$ & Volume serrado $\left(\mathbf{m}^{3}\right)$ & Rendimento médio $\mathbf{( \% )}$ \\
\hline 1 & 1,5581 & 0,9235 & 59,18 a \\
2 & 2,2585 & 1,4340 & $62,69 \mathrm{a}$ \\
3 & 3,1679 & 1,9970 & $63,37 \mathrm{a}$ \\
4 & 4,9529 & 3,2357 & $65,29 \mathrm{a}$ \\
\hline \multicolumn{2}{l}{62,63} \\
\hline \multicolumn{2}{l}{ Médias seguidas da mesma letra não diferem estatisticamente entre si, pelo teste de Tukey a 5\% de probabilidade. }
\end{tabular}

Observa-se, na tabela 6 , que nessa espécie a média de rendimento entre as quatro classes diamétricas foi de $62,63 \%$, não sendo observada diferença estatística em nível de 5\% de probabilidade (Tabela 5), tendo em vista a variabilidade existente entre as toras dentro das classes. O rendimento médio nessa espécie já apresentou a tendência esperada, ou seja, de aumentar de acordo com o aumento da classe diamétrica, tendo sido o menor rendimento observado na classe $1(59,18 \%)$ e o maior na classe 4 $(65,29 \%)$. Mesmo não havendo diferença estatística entre as classes diamétricas, a diferença de aproximadamente seis pontos percentuais entre as classes 1 e 4 é muito importante dentro de uma escala de produção, não só na redução dos custos de produção, mas também na redução dos resíduos gerados pela serraria, os quais, como é prática habitual na região em estudo, são pouco aproveitados. 
O aumento gradativo do rendimento em função do aumento das classes diamétricas deu-se em função da espécie apresentar menos defeitos que o cedrinho, tendo sido observadas, porém, pequenas trincas e rachaduras nas toras, as quais não foram comprometedoras.

Segundo Murara Júnior (2005), dentre os principais fatores que afetam o rendimento em madeira serrada destacam-se a qualidade da tora, as técnicas de desdobro utilizadas, a operação dos equipamentos e os diâmetros das toras. Como, nesta pesquisa, foram utilizados e operados da mesma maneira os mesmos equipamentos e que as espécies seguiam a mesma classificação diamétrica, a qualidade das toras foi o fator determinante para a tendência observada. Dessa maneira, pode-se dizer que a espécie cambará apresentou melhor forma e qualidade que o cedrinho para a obtenção de madeira serrada.

\section{Itaúba (M. itauba)}

Na tabela 7, é apresentada a análise de variância do rendimento em madeira serrada para a espécie itaúba, na qual se pode observar que, assim como ocorreu nas outras duas espécies, não houve diferença estatística entre os rendimentos das quatro classes diamétricas estudadas, para um nível de probabilidade de $5 \%$.

Tabela 7. Análise de variância para o rendimento em madeira serrada entre classes diamétricas, soma de quadrados tipo III, para a espécie itaúba (M. itauba).

Table 7. Analysis of variance for yield in sawnwood between diametric classes, sum of square type III, for itaúba species (M. itauba).

\begin{tabular}{lccccc}
\hline Fonte & Soma dos quadrados & GL & Quadrado médio & Valor-F & Valor-P \\
\hline Efeito principal: & & & & & \\
Classe diamétrica & 192,541 & 3 & 64,1803 & 1,69 & 0,2097 \\
Residual & 608,493 & 16 & 38,0308 & & \\
\hline Total (corrigido) & 801,034 & 19 & & & \\
\hline
\end{tabular}

Observa-se, na tabela 8 , que nessa espécie a média de rendimento entre as quatro classes diamétricas aproximou-se de 54\%, sendo que o menor rendimento foi verificado na classe 1 e o maior na classe 3. Pode-se verificar também que não houve diferença estatística a um nível de $5 \%$ de probabilidade, tendo em vista a variabilidade existente entre as toras dentro das classes. Nessa espécie, ocorreu a tendência do rendimento apresentar uma diferença maior entre as classes 1 e 2 e menor entre as classes 2 e 3, podendo-se dizer que este foi praticamente o mesmo nestas duas classes. Da mesma maneira que para o cedrinho e cambará, não houve diferença estatística para o rendimento entre as classes diamétricas, porém, a diferença entre a classe de menor rendimento (classe 1) e a classe de maior rendimento (classe 3 ) foi de 7,4 pontos percentuais. Tal diferença, numa escala produtiva, pode implicar uma redução de custos considerável, porém, não é esse o alvo deste estudo.

Tabela 8. Volume bruto das toras $\left(\mathrm{m}^{3}\right)$, volume serrado $\left(\mathrm{m}^{3}\right)$ e rendimento médio em madeira serrada $(\%)$ para 4 classes da espécie itaúba (M. itauba).

Table 8. Gross volume of $\operatorname{logs}\left(\mathrm{m}^{3}\right)$, sawnwood volume $\left(\mathrm{m}^{3}\right)$ and average yield in sawnwood $(\%)$ for 4 classes of itaúba species (M. itauba).

\begin{tabular}{lccc}
\hline Classe & Volume da tora $\left(\mathbf{m}^{\mathbf{3}}\right)$ & Volume serrado $\left.\mathbf{( m}^{\mathbf{3}}\right)$ & Rendimento $\%$ \\
\hline 1 & 1,1733 & 0,5856 & $49,73 \mathrm{a}$ \\
2 & 2,1958 & 1,2463 & $56,56 \mathrm{a}$ \\
3 & 3,0352 & 1,7342 & $57,21 \mathrm{a}$ \\
4 & 4,7682 & 2,4924 & $52,13 \mathrm{a}$ \\
\hline Média geral & & 53,90 \\
\hline
\end{tabular}

Médias seguidas da mesma letra não diferem estatisticamente entre si, pelo teste de Tukey a 5\% de probabilidade.

Pode-se observar nas classes 1, 2, 3 e 4 que o volume das toras aumentou de acordo com a classe diamétrica, ocorrendo o mesmo aumento com o volume de madeira serrada. Nas classes 1, 2 e 3 , o rendimento aumentou conforme o aumento da classe diamétrica, mas na classe 4, como no caso do cedrinho, observou-se uma redução no rendimento, ficando este abaixo das classes 2 e 3 . Conseqüentemente, a 
redução do rendimento na classe 4 implicou um menor aproveitamento da tora, gerando maior perda de madeira na forma de resíduo. Essa perda ocorreu também, como observado para o cedrinho, em função de algumas toras apresentarem defeitos, como rachaduras, podridão e ocos (Figura 3).

A figura 4 apresenta um comparativo dos resultados de rendimento em madeira serrada para as 4 classes diamétricas das espécies estudadas.

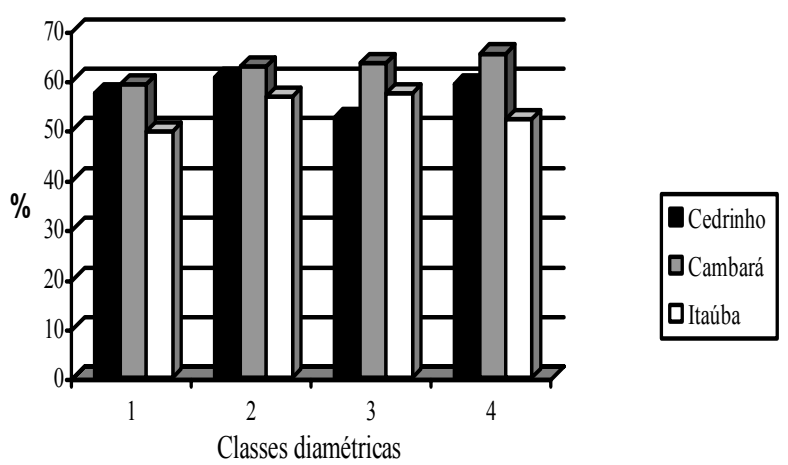

Figura 4. Gráfico comparativo dos resultados de rendimento em madeira serrada (\%) para as 4 classes diamétricas das espécies cedrinho, cambará e itaúba.

Figure 4. Comparative graphic from the results of yield in sawnwood (\%) for the 4 diametric classes of cedrinho, cambará and itaúba species.

Pode-se observar na figura 5 que a espécie cambará apresentou rendimento superior às outras duas espécies em todas as classes diamétricas. O cedrinho, por sua vez, só não foi superior à itaúba na classe 3, para toras de 51 a $60 \mathrm{~cm}$ de diâmetro. Dessa forma, mesmo não havendo nenhuma diferença estatística, pode-se dizer que, em termos de rendimento, a espécie cambará foi a que apresentou melhores resultados, e a itaúba, os piores.

No que diz respeito à tendência do rendimento aumentar de acordo com o aumento do diâmetro das toras, tal situação ocorreu somente para a espécie cambará. A espécie cedrinho apresentou o menor rendimento na classe 3 e a itaúba apresentou o rendimento da classe 4 inferior às classes 2 e 3 .

O rendimento médio das espécies estudadas variou de $49,73 \%$ a $65,29 \%$, sendo que a média entre as espécies foi de 57,96\%. Segundo Iwakiri (1990), num trabalho realizado com rendimento e condições de desdobro de 20 espécies de madeiras da Amazônia, a variação no diâmetro médio das toras entre as 20 espécies estudadas foi na faixa de $38,2 \mathrm{~cm}$ a $68,4 \mathrm{~cm}$. O rendimento médio das 20 espécies estudadas pelo autor variou de $41,9 \%$ a $61,8 \%$, sendo que a média entre as espécies foi de $52,9 \%$, ficando abaixo da média obtida nesta pesquisa.

Segundo Gomide (1974), citado por Tonini e Antonio (2004), rendimentos entre 45 e 55\% são considerados normais para folhosas. Segundo Barbosa (1990), o desdobro primário em Roraima apresentou índices de aproveitamento variando de 38,1 a $68,9 \%$, com uma média estadual de 54,2\%, ficando também abaixo da média aqui estudada, que foi de $57,96 \%$.

\section{Geração de resíduos}

\section{Cedrinho (E. uncinatum)}

Na tabela 9, são apresentados os volumes em resíduos para as 4 classes diamétricas de toras da espécie cedrinho (E. uncinatum), com suas respectivas quantidades na serra-fita, serra circular e outros resíduos, os quais foram considerados como refilos, cascas, aparas e costaneiras. Observa-se que os volumes de resíduos na serra-fita, serra circular e outros resíduos não apresentaram grande variação entre as classes, variando conforme o rendimento em madeira serrada. Observa-se que os outros resíduos entre as classes 1, 2 e 3 foram decrescendo conforme aumentou o rendimento. Porém o mesmo não aconteceu na classe 4, na qual o rendimento foi menor que o das classes 2 e 3 . Conseqüentemente, o volume de outros resíduos aumentou, sendo nesta classe maior que as classes 2 e 3, o que já era esperado. No 
resultado total de resíduos em porcentagem, a soma dos resíduos da serra-fita, serra circular e outros resíduos foi inversa ao valor de rendimento das classes.

Tabela 9. Rendimento (\%), serragem na serra-fita (\%), serragem na serra circular (\%), outros resíduos $(\%)$ e o volume total de resíduos em (\%) de 4 classes da espécie cedrinho (E. uncinatum).

Table 9. Yield (\%), sawdust in the band saw (\%), sawdust in the circular saw (\%), others residues (\%) and total volume of residues (\%) for the 4 classes of cedrinho species (E. uncinatum).

\begin{tabular}{lcccc}
\hline \multirow{2}{*}{ Classe } & \multicolumn{4}{c}{ Volume de resíduos (\%) } \\
\cline { 2 - 5 } & $\begin{array}{c}\text { Serragem } \\
\text { (serra-fita) }\end{array}$ & $\begin{array}{c}\text { Serragem } \\
\text { (serra circular) }\end{array}$ & Outros resíduos & Total de resíduos \\
\hline 1 & 6,61 & 2,73 & 33,36 & 42,70 \\
2 & 6,98 & 2,88 & 29,61 & 39,48 \\
3 & 7,20 & 2,97 & 27,42 & 37,60 \\
4 & 6,82 & 2,82 & 31,25 & 40,88 \\
\hline Média geral & 6,90 & 2,85 & 30,41 & 40,17 \\
\hline
\end{tabular}

Segundo Mendes et al. (2004), ao se desdobrar uma tora, a geração de resíduos é inevitável, sendo que o volume e tipos de pedaços e/ou fragmentos gerados são dependentes de vários fatores. Como exemplo desses fatores, destacam-se o diâmetro das toras e o uso final das peças serradas. Considerando uma tora cilíndrica, e desejando-se retirar apenas um bloco central, o rendimento corresponderia a, no máximo, 63,66\%. Segundo os autores, de modo geral, os resíduos gerados em uma cadeia produtiva de serrados constituem-se em $7 \%$ de casca, $10 \%$ de serragem e $28 \%$ de pedaços, isto sem considerar as perdas na extração da madeira.

\section{Cambará (Q. albiflora)}

$\mathrm{Na}$ tabela 10, são apresentadas as 4 classes diamétricas de toras da espécie Cambará $(Q$. albiflora), com suas respectivas quantidades de resíduos na serra-fita, serra circular e outros resíduos (refilos, cascas, aparas e costaneiras).

Tabela 10.Rendimento (\%), serragem na serra-fita (\%), serragem na serra circular (\%), outros resíduos $(\%)$ e o volume total de resíduos em $(\%)$ de 4 classes da espécie cambará ( $Q$. albiflora $)$.

Table 10. Yield (\%), sawdust in the band saw (\%), sawdust in the circular saw $(\%)$, others residues $(\%)$ and total volume of residues $(\%)$ for the 4 classes of cambará species (Q. albiflora).

\begin{tabular}{ccccc}
\hline \multirow{2}{*}{ Classe } & \multicolumn{4}{c}{ Volume de resíduos (\%) } \\
\cline { 2 - 5 } & $\begin{array}{c}\text { Serragem } \\
\text { (serra-fita) }\end{array}$ & $\begin{array}{c}\text { Serragem } \\
\text { (serra circular) }\end{array}$ & Outros resíduos & $\begin{array}{c}\text { Total de } \\
\text { resíduos }\end{array}$ \\
\hline 1 & 6,83 & 2,82 & 31,18 & 40,82 \\
2 & 7,23 & 2,99 & 27,09 & 37,31 \\
3 & 7,31 & 3,02 & 26,30 & 36,63 \\
4 & 7,53 & 3,11 & 24,07 & 34,71 \\
\hline Média geral & 7,22 & 2,98 & 27,16 & 37,37 \\
\hline
\end{tabular}

Observa-se, na tabela 10 , que nessa espécie a média de rendimento entre as quatro classes diamétricas foi de $62,63 \%$. O rendimento médio nessa espécie já apresentou a tendência esperada, ou seja, de aumentar de acordo com o aumento da classe diamétrica, sendo o menor rendimento observado na classe $1(59,18 \%)$ e o maior na classe $4(65,29 \%)$. O mesmo aconteceu com os resíduos: conforme aumentou o rendimento, diminuiu a média de perdas em resíduos, sendo que a maior porcentagem foi observada na classe $1(40,82 \%)$ e a menor na classe $4(34,71 \%)$.

$\mathrm{O}$ rendimento em madeira serrada sofre influência do tipo de serra, reaproveitamento de aparas e costaneiras, e da metodologia utilizada no desdobro. A utilização de técnicas adequadas pode afetar consideravelmente o rendimento. Resende et al. (1992), citados por Tonini e Antonio (2004), ressaltam que a seleção de toras segundo seu diâmetro e a posterior aplicação de uma estrutura de corte definida em função de determinadas bitolas é condição necessária para a maximização do lucro em uma serraria.

Itaúba (M. itauba) 
Na tabela 11, são apresentadas as 4 classes diamétricas de toras da espécie itaúba (M. itauba), com suas respectivas quantidades de resíduos na serra-fita, serra circular e outros resíduos (refilos, cascas, aparas e costaneiras).

Tabela 11.Rendimento (\%), serragem na serra-fita (\%), serragem na serra circular (\%), outros resíduos $(\%)$ e o volume total de resíduos em $(\%)$ de 4 classes da espécie itaúba (M. itauba).

Table 11. Yield (\%), sawdust in the band saw (\%), sawdust in the circular saw (\%), others residues (\%) and total volume of residues (\%) for the 4 classes of itaúba species (M. itauba).

\begin{tabular}{lcccc}
\hline \multirow{2}{*}{ Classe } & \multicolumn{4}{c}{ Volume de resíduos (\%) } \\
\cline { 2 - 5 } & $\begin{array}{c}\text { Serragem } \\
\text { (serra-fita) }\end{array}$ & $\begin{array}{c}\text { Serragem } \\
\text { (serra circular) }\end{array}$ & Outros resíduos & Total de resíduos \\
\hline 1 & 5,74 & 2,37 & 42,17 & 50,27 \\
2 & 6,53 & 2,69 & 34,23 & 43,44 \\
3 & 6,60 & 2,72 & 33,47 & 42,79 \\
4 & 6,02 & 2,48 & 39,37 & 47,87 \\
\hline Média geral & 6,22 & 2,56 & 37,31 & 46,10 \\
\hline
\end{tabular}

Pode-se observar, na tabela 11, que o rendimento apresentou aumento conforme aumentou a classe de diâmetro entre as classes 1,2 e 3. Porém, como no caso do cedrinho, o rendimento na classe 4 diminuiu, ficando abaixo do rendimento das classes 2 e 3 . O mesmo aconteceu com os valores dos resíduos em serragem na serra-fita, serra circular e outros resíduos, ou seja, conforme aumentou o rendimento, diminuiu a porcentagem em resíduos, o que não aconteceu na classe 4 , seguindo a mesma tendência do cedrinho.

Esse aumento na porcentagem total de resíduos na classe 4 aconteceu em função das duas espécies, cedrinho e itaúba, apresentarem nas toras de maior diâmetro uma incidência maior de defeitos, como ocos e podridão (Figuras 3 e 4). Com isso, ocorreu uma maior quantidade de resíduos em refilos e costaneiras.

Pode-se observar, na tabela 12, que a espécie cambará apresentou rendimento superior às outras duas espécies, porém, não havendo diferença estatística com relação ao cedrinho e diferindo em relação à itaúba, a um nível de probabilidade de 5\%. Essa diferença é observada no resultado total dos resíduos, com o qual o cambará comprovou ter uma perda menor que a das demais espécies. O cedrinho, estatisticamente, não se diferenciou do cambará e da itaúba, mas apresentou uma perda de seis pontos percentuais em relação à itaúba, demonstrando que esta, além de ter menor rendimento em madeira serrada, teve uma maior perda na soma total dos resíduos. Observou-se que a espécie itaúba teve uma menor perda na serra-fita e serra circular, comparando-se com a espécie cedrinho e cambará, mas apresentou uma maior quantidade de outros resíduos, ou seja, na forma de refilos, costaneiras e destopos. Isso ocorreu em vista de as toras dessa espécies apresentarem incidências de ocos, ocorrendo conseqüentemente maior perda em outros resíduos. Dessa forma, analisando-se as diferenças estatísticas, pode-se dizer que, em termos de rendimento, a espécie cambará foi a que apresentou melhores resultados, e a itaúba, os piores.

Tabela 12.Comparativo entre rendimento (\%), resíduos de serra-fita $(\%)$, serra circular (\%), outros resíduos $(\%)$ e o total de resíduos $(\%)$ entre as espécies de cedrinho (E. uncinatum), cambará (Q. albiflora) e itaúba (M. itauba).

Table 12. Comparative between yield (\%), residues providing from band saw, circular saw (\%), others residues $(\%)$ and the total residues $(\%)$ between species of cedrinho (E. uncinatum), cambará (Q. albiflora) e itaúba (M. itauba).

\begin{tabular}{lccccc}
\hline \multirow{2}{*}{ Espécie } & $\begin{array}{c}\text { Rendimento } \\
\text { médio (\%) }\end{array}$ & $\begin{array}{c}\text { Serragem } \\
\text { (serra-fita) }\end{array}$ & $\begin{array}{c}\text { Volume de resíduos (\%) } \\
\text { (serra circular) }\end{array}$ & $\begin{array}{c}\text { Outros } \\
\text { resíduos }\end{array}$ & $\begin{array}{c}\text { Total de } \\
\text { resíduos }\end{array}$ \\
\hline Cedrinho & $59,83 \mathrm{a}$ & $6,90 \mathrm{a}$ & $2,85 \mathrm{a}$ & $30,41 \mathrm{ab}$ & 40,17 \\
Cambará & $62,63 \mathrm{a}$ & $7,22 \mathrm{a}$ & $2,98 \mathrm{a}$ & $27,16 \mathrm{a}$ & 37,37 \\
Itaúba & $53,90 \mathrm{~b}$ & $6,22 \mathrm{~b}$ & $2,56 \mathrm{~b}$ & $37,31 \mathrm{~b}$ & 46,10 \\
\hline Média geral & 58,79 & 6,78 & 2,80 & 31,63 & 41,21 \\
\hline
\end{tabular}

Médias seguidas da mesma letra, na coluna, não diferem estatisticamente entre si, pelo teste de Tukey a 5\% de probabilidade. 
Pode-se verificar, na tabela 12, que a maior perda em outros resíduos ocorreu na espécie itaúba e a menor no cambará, porém esta espécie apresentou maior formação de resíduos na forma de serragem, tanto na serra-fita como na serra circular. A itaúba, na soma total dos resíduos, alcançou 46,09\%, quase dez pontos percentuais acima da espécie cambará, que apresentou a menor perda $(37,37 \%)$, demonstrando, para fins de aproveitamento em rendimento, ser uma espécie melhor que as demais.

\section{CONCLUSÕES}

De acordo com os resultados obtidos, pode-se concluir que:

- As classes diamétricas, estatisticamente, não influenciaram o rendimento, mas houve tendência deste ser inferior em relação às classes diamétricas estudadas.

- A espécie cedrinho não apresentou diferenças estatísticas nos rendimentos obtidos para as quatro classes diamétricas estudadas.

- Para a espécie cambará, houve uma tendência de aumento no rendimento de acordo com o aumento da classe diamétrica, apesar de não haver diferença estatística entre as mesmas.

- A itaúba apresentou a mesma tendência do cedrinho de aumento do rendimento entre as classes 1 e 3 e redução na classe 4, em função dos defeitos nas toras, embora não havendo diferença estatística entre as quatro classes estudadas.

- A espécie cambará, mesmo não apresentando diferença estatística com o cedrinho, foi a que apresentou o melhor rendimento em madeira serrada.

- A espécie itaúba foi a que apresentou menores resultados em rendimento de madeira serrada.

- Toras de maiores diâmetros das espécies cedrinho e itaúba apresentaram defeitos com rachaduras e ataques por agentes xilófagos, provocando a redução no rendimento em madeira serrada.

- Em termos de geração de resíduos na forma de serragem, somente a itaúba diferiu estatisticamente das demais, diferindo também na geração de outros resíduos em relação ao cambará, possivelmente em função de sua maior densidade.

- A espécie itaúba, com menores índices de rendimento, conseqüentemente foi a que apresentou a maior geração de resíduos durante as operações de desdobro.

\section{REFERÊNCIAS}

ABIMCI. Estudo Setorial 2003 - Produtos de madeira sólida.

BARBOSA, R. I. Análise do setor madeireiro do estado de Roraima. Acta Amazônica, Manaus, v. 20, n. 9,p. 193-209, 1990.

BARBOSA, A. P.; VIANEZ, B. F.; VAREJÃO, M. de J.; ABREU, R. S. de. Consideração sobre o perfil tecnológico do setor madeireiro na Amazônia Central. Manaus: [s.n.], 2001.

FONTES, P. J. P. Aproveitamento energético da madeira derivada dos desmatamentos em Rondônia. Brasília: IBAMA/DIRPED/LPF, 1989. (Série técnica, n. 9).

FONTES, P. J. P. Auto-suficiência energética em serraria de Pinus e aproveitamento dos resíduos. Dissertação (Mestrado em Ciências Florestais) - Setor de Ciências Agrárias, Universidade Federal do Paraná, Curitiba 1994.

GOMIDE, J. L. Serraria. Viçosa: UFV, 1974. 119p.

IBDF. Madeiras da amazônia, características e utilização: Estação Experimental de Curuá-Uma. Brasília, 1998.

IWAKIRI, S. Rendimento e condições de desdobro de 20 espécies de madeiras da Amazônia. Acta Amazônica, Manaus, n. 20, p. 271-281, 1990. 
LORENZI, H. Árvores brasileiras: manual de identificação e cultivo de plantas arbóreas nativas do Brasil. 2.ed. Nova Odessa:Plantarum, v.1. 1998.

MURARA JUNIOR, M. I. Desdobro de toras de pinus utilizando diagramas de corte para diferentes classes diamétricas. 66f. Dissertação (Mestrado em Ciências Florestais) - Setor de Ciências Agrárias, Universidade Federal do Paraná, Curitiba, 2005.

OLIVEIRA. A. D.; MARTINS, E. P.; SCOlfARO, J. R. S.; RESENDE, J. L. P.; SOUZA, A. N. de. Viabilidade Econômica de Serrarias que Processam Madeiras Florestais Nativas - O Caso do Município de Jaru, Estado de Rondônia. Cerne, Lavras, v. 9, n. 1, p.1-15, 2003.

PEIXOTO, C. D.; IWAKIRI, S. Dados e índices da indústria madeireira do estado do Amazonas. Manaus: INPA/CPPF, 1984. 32 p. (Série Técnica, n. 4).

REIS. M. S. Mesa Redonda Internacional, Oportunidade e Limitações para o Desenvolvimento da Indústria Baseada em Madeiras Tropicais na América Latina. 20-23 fevereiro, 1989. Brasília DF.

ROCHA, M. P. Eucalyptus grandis Hill ex Maiden e Eucalyptus dunnii Maiden como fontes de matéria prima para serrarias. 185f. Tese (Doutorado em Ciências Florestais) - Setor de Ciências Agrárias, Universidade Federal do Paraná, Curitiba, 2000.

TONINI, H.; ANTONIO, L. M. M. F. Rendimento em madeira serrada de cupiuba (Goupia glabra), caferana (Erisma uncinatum) e angelim-pedra (Dinizia excelsa). Boa Vista: Embrapa Roraima, 2004. (Comunicado Técnico, n.7).

WIPIESKI, C. J.; LOPES, F. S.; OLIVEIRA JÚNIOR, R. SISCORTE: uma ferramenta de otimização de serrarias. Curitiba: STCP, 2002. p. 22-25. (Informativo. n. 6). 